DOI: 10.12731/2658-6649-2019-11-4-24-37

УДК 575.224.22

\title{
АССОЦИАЦИЯ \\ ПОЛИМОРФИЗМА RS3846663 ГЕНА \\ ГМГ-КОА-РЕДУКТАЗЫ С ЭФФЕКТИВНОСТЬЮ \\ ТЕРАПИИ СТАТИНОМ У БОЛЬНЫХ ИШЕМИЧЕСКОЙ БОЛЕЗНЬЮ СЕРДЦА
}

\author{
Оседко А.В., Котловский М.Ю., \\ Оседко О.Я., Дыгай А.М.
}

Целью работы являлось изучение связи вариантов полиморфного маркера rs3846663 гена ГМГ-КоА-редуктазы с эффективностью статинотерапии. В группу больных ишемической болезни сердиа были отобрань 127 человек (59 женщин, 68 мужчин). Для идентификации одноточечного нуклеотидного полиморфизма использовали реакиию минисеквенирования с последующей детекичей продуктов реакции с использованием метода времяпролетной масс-спектрометрии с матрично-активированной лазерной десорбцией/ионизаичей.

В проведённом исследовании статин достоверно снизил содержание общего холестерина, липопротеинов низкой плотности и триглицеридов, как при одном, так и при двух месяцах лечения. Установлено отсутствие влияния носительства генотипов СТ и ТТ полиморфного маркера rs3846663 гена ГМГ-КоА-редуктазы на изменение практически всех показателей спектра липопротеинов и общего холестерина при терапии статином, независимо от ее продолжительности. Была зафиксирована слабая тендениия к увеличению липопротеинов высокой плотности у носителей гетерозиготы СТ при лечении статином в течение одного месяия.

Помимо этого, было установлено отсутствие достоверной связи между носительством гетерозиготного генотипа СТ и гомозиготы TT и достижением иелевых значений липопротеинов и общего холестерина при лечении симвастатином, независимо от продолжительности.

Ключевые слова: ГМГ-КоА-редуктаза; симвастатин; ишемическая болезнь сердия; гиперхолестеринемия; rs3846663; холестерин. 


\title{
ASSOCIATION OF POLYMORPHISM RS3846663 IN HMG-COA REDUCTASE GENE WITH THE EFFECTIVENESS OF STATIN THERAPY IN PATIENTS WITH CORONARY HEART DISEASE
}

\author{
Osedko A.V., Kotlovskiy M.Y., \\ Osedko O.Y., Dygai A.M.
}

The purpose of this work was to study the associations of RS3846663 variants in the HMG-CoA reductase gene with effectiveness of statin therapy. For the coronary heart disease patients group, 127 subjects (59 females and 68 males) were selected. In order to identify single nucleotide polymorphism, minisequencing was applied with matrix-assisted laser desorption/ionisation time-of-flight mass spectrometry (MALDI-ToF/MS) for subsequent detection of the reaction products.

In this study, the statin significantly reduced total cholesterol, low density lipoprotein and triglyceride levels, both after one month and two months of treatment. It was established that carrying CC and TT genotypes of RS3846663 in $H M G-C o A$ reductase gene had no impact on the change in total cholesterol and almost all values in the spectrum of lipoproteins during statin therapy, regardless of its duration. A weak tendency to an increase in high-density lipoproteins was observed in heterozygous CT carriers after one month of statin treatment.

In addition, no significant association was found between carrying heterozygous CT genotype and TT homozygote and achievement of target levels of lipoproteins and total cholesterol during simvastatin treatment, regardless of its duration.

Keywords: HMGCR; simvastatin; coronary heart disease; hypercholesterolemia; rs3846663; cholesterol.

Сердечно-сосудистые заболевания (СС3) являются ведущей причиной смертности во всем мире, в том числе и в России, [1]. Большинство заболеваний сердечно-сосудистой системы имеет мультифакторную природу, т.е. в их формирование вовлечены многочисленные генетические системы и средовые факторы $[2,3,4]$. Одна из актуальных задач современной медицины это изучение ассоциаций полиморфных маркеров генов с предрасположенностью к развитию патологии, а также эффективностью медикаментозной терапии для предупреждения развития СС3, уменьше- 
ние риска осложнений, прогнозирование эффективности медикаментозной терапии $[5,6,7,8]$.

ГМГ-КоА-редуктаза является одним из ключевых ферментов, регулирующих синтез ХС в печени на этапе превращения 3-гидрокси-3-метилглютарил коэнзима А (ГМГ-КоА) в мевалоновую кислоту путем двухступенчатого восстановления за счет NADH. Помимо того, что эта реакция является скорость-лимитирующей стадией на пути синтеза холестерина, данный фермент является мишенью для гиполипидемических препаратов - статинов [9]. Механизм действия данного препарата связан с ингибированием активности 3-гидрокси-3-метил-глутарил коэнзим А - редуктазы (ГМК-КоА - редуктазы) - лимитирующего фермента начальной стадии биосинтеза холестерина [10].

Полиморфные варианты гена ГМК-КоА - редуктазы могут влиять на метаболизм и транспорт липопротеинов плазмы и эффективность терапии статинами $[5,11,12]$ Исследования, проведенные в различных популяциях, доказали наличие связи между некоторыми вариантами полиморфизмов гена ГМК-КоА - редуктазы и липидным профилем $[3,4,5,15,16,17]$, а также ассоциации между определенными вариантами полиморфизмов и повышенным риском развития сердечно-сосудистых заболеваний, и эффективностью их медикаментозной терапии $[18,19,20]$.

Цель настоящего исследования заключалась в установлении ассоциации вариантов полиморфного маркера rs3846663 гена ГМГ-КоА-редуктазы с эффективностью статинотерапии.

\section{Материалы и методы исследования}

Изучение зависимости терапевтического эффекта симвастатина от полиморфизмов гена ГМГ-КоА-редуктазы проводилось в рамках открытого, рандомизированного, контролируемого и параллельного исследования на базе ЦНИЛ ФГБОУ ВО КрасГМУ им. проф. В.Ф. Войно-Ясенецкого Минздрава России (г. Красноярск), КГБУЗ «КМКБ № 20 им. И.С. Берзона (г. Красноярск), КГБУЗ «Красноярская поликлиника № 14» (г. Красноярск). В соответствии с требованиями Хельсинской декларации Всемирной медицинской ассоциации (1964) и ее последующих редакций, проведение исследования было утверждено на заседании локального этического комитета ГБОУ ВПО КрасГМУ им. проф. В. Ф. Войно-Ясенецкого Минздрава России (выписка из протокола заседания локального этического комитета №41/2012 от 21.06.2012). Все участники исследования подписывали информированное согласие. Протокол исследования соответствовал этическим принципам и нормам проведения биомедицинских исследований. 
Для изучения оценки распространенности и ассоциации полиморфизма rs3846663 гена HMGCR была обследована группа пациентов, состоящая из 127 человек (59 женщин, 68 мужчин), больных ИБС. Средний возраст пациентов данной группы составлял $(60,19 \pm 9,81)$ года. Критериями включения в исследование для представителей данной группы являлся возраст от 40 до 70 лет; верифицированный диагноз ИБС (стенокардия напряжения 1-2-го функционального класса и инфаркт миокарда давностью более 6 мес); наличие дислипидемии (IIa, IIв, III, IV типов, при $\mathrm{OXC}>5,2$ ммоль/л, ТГ $>1,7$ ммоль/л). Критериями исключения являлись инфаркт миокарда в анамнезе; прогрессирующая стенокардия; острое нарушение мозгового кровообращения и транзиторная ишемическая атака; тромбоэмболия легочной артерии менее чем за 6 мес до обследования; стенокардия напряжения 3-4-го функционального класса; тяжелые нарушения функции печени и почек; острые и хронические заболевания в стадии обострения; гипотиреоидизм, порфирия, миопатия, повышенная активность ферментов АСТ и АЛТ более 3 верхних пределов нормы; злоупотребление алкоголем.

Критериями преждевременного прекращения участия в исследовании было: возникновение осложнений от приема симвастатина и отсутствие дальнейшего желания к сотрудничеству.

Пациентам назначали холестеринснижающий препарат «СимваГЕКCAЛ» (Hexal AG, Германия, рег. номер П № 015775/01 от 18.06.2004) в дозе 40 мг/сут. До приема препарата проводился забор крови для проведения биохимического, развернутого анализа, теста толерантности к углеводам. Повторный забор крови для биохимического, развернутого анализа крови осуществляли через 1 и 2 месяца. Также проводили забор крови для молекулярно-генетического исследования, целью которого было идентифицировать генотипы полиморфизмов гена ГМГ-КоА-редуктазы.

В проведенном исследовании анализировали целевые уровни липопротеинов и ОХС в соответствии с Российскими национальными рекомендациями по диагностике и коррекции нарушений липидного обмена с целью профилактики и лечения атеросклероза (V пересмотр, 2012) [21].

Для генетического анализа использовался образец ДНК, выделенный из венозной крови пациента при помощи стандартного фенол-хлороформного метода. Для проведения последующих этапов молекулярно-генетических исследований использовался специальный набор для идентификации однонуклеотидных полиморфизмов (ООО НПФ «ЛИТЕХ»). Согласно ин- 
струкции, последовательно проводили реакции амплификации, дефосфорилирования и минисеквенирования для дальнейшей идентификации полиморфизмов на времяпролетном масс-спектрометре autoflex IV (Bruker Daltonics, Германия).

Полученные данные подвергались статистической обработке на персональном компьютере с применением прикладной программы IBM SPSS Statistics 20 (США).

Статистическую значимость различий между показателями независимых выборок оценивали по непараметрическому критерию Манна-Уитни. Описание производили с помощью подсчета медианы (Me) и интерквартального размаха в виде 25 и 75 процентилей (Q1 и Q3). Различие считали статистически значимым при уровне $\mathrm{p} \leq 0,05$.

Отличие показателей липопротеинов и ОХС до и после лечения симвастатином определяли, сравнивая две связанные выборки методом Вилкоксона. Во всех случаях различия сравниваемых величин считали статистически значимыми при уровне $\mathrm{p} \leq 0,05$.

Качественные критерии представлены в виде абсолютных значений и их процентных долей. Для определения статистической значимости различий между качественными признаками применяли критерий хи-квадрат $(\chi 2)$. Когда объем выборки не превышал 10 случаев, применяли точный тест Фишера. Различия в распределении частот аллелей и генотипов изучаемых генов между группами считали статистически значимыми при уровне $\mathrm{p} \leq 0,05$. Подсчитывали отношение шансов для вероятности наступления события. Был указан их 95\%-й доверительный интервал (ДИ).

Величину изменения концентрации ОХС, ХC-ЛПНП, ХС-ЛПВП и ТГ при лечении симвастатином для определения пропорциональности его влияния при разных генотипах, вычисляли как разницу между значением данных показателей $(\Delta)$ до и после статинотерапии.

\section{Результаты и обсуждение}

В первую очередь было проведен анализ эффективности терапии по каждому из генотипов полиморфного маркера rs3846663. Было выявлено, что статин, независимо от наличия патологического аллеля Т полиморфного маркера rs3846663 гена ГМГ-КоА-редуктазы, достоверно снизил содержание ОХС, ХC-ЛПНП и ТГ, как при одном, так и при двух месяцах лечения. В то же время неизменным оставалось содержание ХС-ЛПВП (Таблица 1). 
Таблица 1.

Обусловленные полиморфизмом rs3846663 особенности изменения спектра липопротеинов и общего холестерина сыворотки крови у больных ИБС после терапии статином, $M e[Q 1 ; Q 3]$

\begin{tabular}{|c|c|c|c|c|c|}
\hline Показатель & Генотип & $\begin{array}{c}\text { Количество } \\
\text { пациентов }\end{array}$ & До лечения & $1 \mathrm{мес}$ & 2 мес \\
\hline & $C C$ & 44 & $\begin{array}{c}5,31 \\
{[4,54 ; 5,88]}\end{array}$ & $\begin{array}{c}3,75 \\
{[3,22 ; 4,54]^{*}}\end{array}$ & $\begin{array}{c}3,81 \\
{[3,29 ; 4,63]^{*}}\end{array}$ \\
\hline \multirow[t]{3}{*}{$\mathrm{OXC}$} & $C T$ & 57 & $\begin{array}{c}5,68 \\
{[4,77 ; 6,45]}\end{array}$ & $\begin{array}{c}4,04 \\
{[3,41 ; 4,60]^{*}}\end{array}$ & $\begin{array}{c}4,21 \\
{[3,63 ; 4,87]^{*}}\end{array}$ \\
\hline & $T T$ & 26 & $\begin{array}{c}5,27 \\
{[4,59 ; 6,32]}\end{array}$ & $\begin{array}{c}4,08 \\
{[3,13 ; 4,62]^{*}}\end{array}$ & $\begin{array}{c}3,93 \\
{[3,47 ; 4,39]^{*}}\end{array}$ \\
\hline & $C C$ & 44 & $\begin{array}{c}3,41 \\
{[2,51 ; 3,99]}\end{array}$ & $\begin{array}{c}2,10 \\
{[1,62 ; 2,69]^{*}}\end{array}$ & $\begin{array}{c}2,02 \\
{[1,69 ; 2,66]^{*}}\end{array}$ \\
\hline \multirow[t]{3}{*}{ ХС-ЛПНП } & $C T$ & 57 & $\begin{array}{c}3,43 \\
{[2,63 ; 4,57]}\end{array}$ & $\begin{array}{c}2,10 \\
{[1,62 ; 2,76]^{*}}\end{array}$ & $\begin{array}{c}2,36 \\
{[1,82 ; 2,80]^{*}}\end{array}$ \\
\hline & $T T$ & 26 & $\begin{array}{c}3,38 \\
{[2,35 ; 4,28]}\end{array}$ & $\begin{array}{c}1,98 \\
{[1,30 ; 2,56]^{*}}\end{array}$ & $\begin{array}{c}1,78 \\
{[1,47 ; 2,57]^{*}}\end{array}$ \\
\hline & $C C$ & 44 & $\begin{array}{c}1,28 \\
{[1,10 ; 1,47]}\end{array}$ & $\begin{array}{c}1,29 \\
{[0,98 ; 1,51]}\end{array}$ & $\begin{array}{c}1,25 \\
{[1,02 ; 1,54]}\end{array}$ \\
\hline \multirow[t]{3}{*}{ ХС-ЛПВП } & $C T$ & 57 & $\begin{array}{c}1,40 \\
{[1,07 ; 1,61]}\end{array}$ & $\begin{array}{c}1,40 \\
{[1,14 ; 1,71]}\end{array}$ & $\begin{array}{c}1,31 \\
{[1,13 ; 1,61]}\end{array}$ \\
\hline & $T T$ & 26 & $\begin{array}{c}1,37 \\
{[1,12 ; 1,68]}\end{array}$ & $\begin{array}{c}1,34 \\
{[1,15 ; 1,56]}\end{array}$ & $\begin{array}{c}1,48 \\
{[1,18 ; 1,68]}\end{array}$ \\
\hline & $C C$ & 44 & $\begin{array}{c}1,34 \\
{[0,92 ; 2,02]}\end{array}$ & $\begin{array}{c}1,16 \\
{[0,75 ; 1,62]^{*}}\end{array}$ & $\begin{array}{c}1,17 \\
{[0,91 ; 1,71]^{\#}}\end{array}$ \\
\hline \multirow[t]{2}{*}{ ТГ } & $C T$ & 57 & $\begin{array}{c}1,59 \\
{[1,03 ; 2,15]}\end{array}$ & $\begin{array}{c}1,15 \\
{[0,86 ; 1,56]^{*}}\end{array}$ & $\begin{array}{c}1,28 \\
{[0,87 ; 1,64]^{*}}\end{array}$ \\
\hline & $T T$ & 26 & $\begin{array}{c}1,55 \\
{[1,29 ; 2,07]}\end{array}$ & $\begin{array}{c}1,22 \\
{[0,96 ; 1,60]^{*}}\end{array}$ & $\begin{array}{c}1,20 \\
{[0,89 ; 2,05]^{\#}}\end{array}$ \\
\hline
\end{tabular}

Примечание. Здесь и далее отличие от показателей, наблюдаемых до лечения, обозначено: $\wedge-p \leq 0,05 ;{ }^{*}-p \leq 0,01 ;{ }^{*}-p \leq 0,001$.

При сравнении показателей липидного спектра крови, было зафиксировано увеличение концентрации ХС-ЛПВП у носителей гетерозиготы $C T$ при лечении статином в течение 1 мес. Таким образом, была отмечена слабая тенденция к увеличению содержания ХС-ЛПВП у больных ИБС носителей гетерозиготного генотипа (Таблица 2). 
Таблииа 2.

Обусловленная полиморфизмом rs3846663 величина изменения ( $\Delta$ ) спектра липопротеинов и общего холестерина сыворотки крови у больных ИБС после терапии статином, Ме [Q1; Q3]

\begin{tabular}{|c|c|c|c|c|c|}
\hline Показатель & Лечение, мес & Генотип & $\begin{array}{c}\text { Количество } \\
\text { пациентов }\end{array}$ & $\Delta$, ммоль/л & $p$ \\
\hline \multirow{6}{*}{ OXC } & & $C C$ & 44 & $1,55[0,69 ; 2,18]$ & \multirow{2}{*}{0,54} \\
\hline & 1 & $C T$ & 57 & $1,84[0,62 ; 2,27]$ & \\
\hline & & $T T$ & 26 & $1,95[0,82 ; 2,05]$ & 0,35 \\
\hline & & $C C$ & 44 & $1,22[0,81 ; 2,05]$ & 089 \\
\hline & 2 & $C T$ & 57 & $1,43[0,30 ; 2,43]$ & 0,89 \\
\hline & & $T T$ & 26 & $1,47[0,69 ; 2,23]$ & 0,82 \\
\hline \multirow{6}{*}{ ХС-ЛПНП } & & $C C$ & 44 & $1,23[0,54 ; 1,97]$ & \multirow{2}{*}{0,15} \\
\hline & 1 & $C T$ & 57 & $1,74[0,59 ; 2,41]$ & \\
\hline & & $T T$ & 26 & $1,70[0,61 ; 2,37]$ & 0,22 \\
\hline & & $C C$ & 44 & $1,21[0,51 ; 1,89]$ & \multirow{2}{*}{0,72} \\
\hline & 2 & $C T$ & 57 & $1,39[0,33 ; 2,20]$ & \\
\hline & & $T T$ & 26 & $1,71[0,63 ; 2,08]$ & 0,49 \\
\hline \multirow{6}{*}{ ХС-ЛПВП } & & $C C$ & 44 & $-0,06[-0,18 ; 0,14]$ & \multirow{2}{*}{0,03} \\
\hline & 1 & $C T$ & 57 & $0,05[-0,02 ; 0,16]$ & \\
\hline & & $T T$ & 26 & $0,03[-0,11 ; 0,13]$ & 0,34 \\
\hline & & $C C$ & 44 & $-0,02[-0,19 ; 0,19]$ & 0.46 \\
\hline & 2 & $C T$ & 57 & $0,01[-0,17 ; 0,23]$ & 0,40 \\
\hline & & $T T$ & 26 & $-0,05[-0,12 ; 0,20]$ & 0,32 \\
\hline \multirow{6}{*}{ ТГ } & & $C C$ & 44 & $0,27[-0,08 ; 0,67]$ & \multirow{2}{*}{0,78} \\
\hline & 1 & $C T$ & 57 & $0,31[-0,05 ; 0,66]$ & \\
\hline & & $T T$ & 26 & $0,33[0,07 ; 0,56]$ & 0,75 \\
\hline & & $C C$ & 44 & $0,20[-0,18 ; 0,57]$ & \multirow{2}{*}{0,68} \\
\hline & 2 & $C T$ & 57 & $0,22[-0,05 ; 0,54]$ & \\
\hline & & $T T$ & 26 & $0,35[-0,03 ; 0,65]$ & 0,46 \\
\hline
\end{tabular}

На следующем этапе был проведен анализ достижения целевых уровней липидов у пациентов с ИБС в зависимости от генотипов полиморфного маркера при медикаментозной терапии, в ходе чего было выявлено отсутствие достоверной связи между наличием патологического аллеля Т и достижением целевых значений липопротеинов и ОХС при лечении симвастатином, независимо от его продолжительности (Таблица 3). 
Таблица 3.

Обусловленное полиморфизмом rs3846663 соответствие целевой норме содержания липопротеинов и общего холестерина сыворотки крови у больных ИБС после терапии статином

\begin{tabular}{|c|c|c|c|c|c|c|c|c|c|c|c|}
\hline \multirow{3}{*}{ Показатель } & \multirow{3}{*}{ 志 } & \multicolumn{5}{|c|}{$1 \mathrm{мес}$} & \multicolumn{5}{|c|}{2 мес } \\
\hline & & \multicolumn{2}{|c|}{$\begin{array}{c}\text { Повышен- } \\
\text { ное содер- } \\
\text { жание }\end{array}$} & \multicolumn{2}{|c|}{ Норма } & \multirow[t]{2}{*}{$p$} & \multicolumn{2}{|c|}{$\begin{array}{c}\text { Повышен- } \\
\text { ное содер- } \\
\text { жание }\end{array}$} & \multicolumn{2}{|c|}{ Норма } & \multirow[t]{2}{*}{$p$} \\
\hline & & Абс. & $\%$ & Абс. & $\%$ & & Абс. & $\%$ & Абс. & $\%$ & \\
\hline & $C C$ & 19 & 43,2 & 25 & 56,8 & \multirow{2}{*}{0,2} & 19 & 43,2 & 25 & 56,8 & \multirow{2}{*}{0,07} \\
\hline \multirow[t]{3}{*}{$\mathrm{OXC}$} & $C T$ & 32 & 56,1 & 25 & 43,9 & & 35 & 61,4 & 22 & 38,6 & \\
\hline & $T T$ & 14 & 53,8 & 12 & 46,2 & 0,39 & 12 & 46,2 & 14 & 53,8 & 0,81 \\
\hline & $C C$ & 27 & 61,4 & 17 & 38,6 & \multirow{2}{*}{0,46} & 32 & 72,7 & 12 & 27,3 & \multirow{2}{*}{0,76} \\
\hline \multirow[t]{3}{*}{ ХС-ЛПНП } & $C T$ & 39 & 68,4 & 18 & 31,6 & & 43 & 75,4 & 14 & 24,6 & \\
\hline & $T T$ & 14 & 53,8 & 12 & 46,2 & 0,54 & 13 & 50 & 13 & 50 & 0,06 \\
\hline & $C C$ & 14 & 31,8 & 30 & 68,2 & \multirow{2}{*}{0,1} & 15 & 34,1 & 29 & 65,9 & \multirow{2}{*}{0,79} \\
\hline \multirow[t]{3}{*}{ ХС-ЛПВП } & $C T$ & 10 & 17,5 & 47 & 82,5 & & 18 & 31,6 & 39 & 68,4 & \\
\hline & $T T$ & 6 & 23,1 & 20 & 76,9 & 0,59 & 6 & 23,1 & 20 & 76,9 & 0,42 \\
\hline & $C C$ & 10 & 22,7 & 34 & 77,3 & \multirow{2}{*}{0,84} & 11 & 25,0 & 33 & 75,0 & \multirow{2}{*}{0,96} \\
\hline \multirow[t]{2}{*}{$\mathrm{T \Gamma}$} & $C T$ & 12 & 21,1 & 45 & 78,9 & & 14 & 24,6 & 43 & 75,4 & \\
\hline & $T T$ & 4 & 15,4 & 22 & 84,6 & 0,46 & 6 & 23,1 & 20 & 76,9 & 0,86 \\
\hline
\end{tabular}

Таким образом, в процессе исследования установлено отсутствие влияния патологического аллеля Т полиморфизма rs3846663 гена ГМГ-КоА-редуктазы на изменение практически всех показателей спектра липопротеинов и ОХС сыворотки крови (исключение ЛПВП) при терапии статином, независимо от ее продолжительности.

\section{Заключение}

В рамках настоящего исследования была изучена ассоциация полиморфизма rs3846663 гена HMGCR с эффективностью терапии симвастатином, который относится к числу широко применяемых и хорошо изученных препаратов в течение продолжительного времени клинического использования.

Изучение связи генетических характеристик полиморфизма rs 3846663 гена ГМГ-КоА-редуктазы с эффективностью статинотерапии представляет интерес для разработки новых подходов оптимизации и персонализации лечения.

Статин, независимо от наличия патологического аллеля Т полиморфного маркера rs3846663 гена ГМГ-КоА-редуктазы, статистически значимо 
снижал содержание ОХС, ХС-ЛПНП и ТГ, как при одном, так и при двух месяцах лечения. Данное снижение было пропорциональным.

Была зафиксирована слабая тенденция к увеличению ХС-ЛПВП у носителей патологической гетерозиготы СТ при лечении статином в течение одного месяца.

Помимо этого, исследование показало отсутствие достоверной связи между наличием патологического аллеля Т и достижением целевых значений липопротеинов и ОХС при лечении симвастатином, независимо от его продолжительности.

Таким образом, в результате проведенного нами исследования установлено отсутствие влияния патологического аллеля Т полиморфизма rs3846663 гена ГМГ-КоА-редуктазы на изменение практически всех показателей спектра липопротеинов и ОХС сыворотки крови (за исключением ЛПВП, 1 мес лечения) при терапии статином, независимо от ее продолжительности.

\section{Список литературы}

1. Всемирная Организация Здравоохранения. Информационный бюллетень № 317 «Сердечно-сосудистые заболевания». URL: http://www.who.int/ mediacentre/factsheets/fs317/ru/index.html (дата обращения: 15.09.2018).

2. Common variants at 30 loci contribute to polygenic dyslipidemia / Kathiresan S., Willer C.J., Peloso G.M. et al. // Nat Genet. 2009. Vol. 41(1), pp. 56-65.

3. Polymorphisms associated with cholesterol and risk of cardiovascular events / Kathiresan S., Melander O., Anevski D. et al. // N Engl J Med. 2008. V. 358, pp. 1240-1249. [PubMed: 18354102].

4. Six new loci associated with blood low-density lipoprotein cholesterol, high-density lipoprotein cholesterol or triglycerides in humans / Kathiresan S., Melander O., Guiducci C. et al. // Nat Genet. 2008. Vol. 40(2), pp. 189-197.

5. Cost effectiveness of HMG-CoA reductase inhibitor (statin) treatment related to the risk of coronary heart disease and cost of drug treatment / Pickin D.M., McCabe C.J., Rams L.E. et al. // Heart. 1999. Vol. 82, pp. 325-332.

6. Pharmacogenetic meta-analysis of genome-wide association studies of LDL cholesterol response to statins / Postmus I., Trompet S., Deshmukh H.A. et al. // Nat Commun. 2014. Vol. 5. P. 5068.

7. Comprehensive Whole-Genome and Candidate Gene Analysis for Response to Statin Therapy in the Treating to New Targets (TNT) Cohort / Thompson J.F., Hyde C.L., Wood L.S. et al. // Circulation Cardiovascular Genetics. 2009. Vol. 2, pp. 173-181. [PubMed: 20031582]. 
8. Effect of naturally random allocation to lower low-density lipoprotein cholesterol on the risk of coronary heart disease mediated by polymorphisms in NPC1L1, HMGCR, or both: a $2 \times 2$ factorial Mendelian randomization study / Ference B.A. et al. // Journal of the American College of Cardiology. 2015. Vol. 65, N. 15, pp. 1552-1561.

9. Würtz P., Wang Q., Soininen P. Metabolomic profiling of statin use and genetic inhibition of HMG-CoA reductase // Journal of the American College of Cardiology. 2016. vol. 67. no 10, pp. 1200-1210.

10. Burkhardt R., Kenny E.E., Lowe J.K. Common SNPs in HMGCR in micronesians and whites associated with LDL-cholesterol levels affect alternative splicing of exon13 // Arteriosclerosis, Thrombosis, and Vascular Biology. 2008. vol. 28, pp. 2078-2084.

11. Controlling cholesterol synthesis beyond 3-hydroxy-3-methylglutaryl-CoA reductase (HMGCR) / Sharpe L.J., Brown A.J. // Journal of Biological Chemistry. 2013. T. 288, №26, pp. 18707-18715.

12. Effect of HMGCR variant alleles on low-density lipoprotein cholesterol-lowering response to atorvastatin in healthy Korean subjects / Chung J.Y., Cho S.K., Oh E.S. et al. // J Clin Pharmacol. 2012. Vol. 52, pp. 339-346.

13. Medina M.W., Krauss R.M. The role of HMGCR alternative splicing in statin efficacy // Trends in Cardiovascular Medicine. 2009. vol. 19, pp. 173-177.

14. Role of rs3846662 and HMGCR alternative splicing in statin efficacy and baseline lipid levels in familial hypercholesterolemia / Leduc V., Bourque L., Poirier J., Dufour R. // Pharmacogenetics and Genomics. 2016. vol. 26. no 1, pp. 109-119.

15. A paucimorphic variant in the HMG-CoA reductase gene is associated with lipid-lowering response to statin treatment in diabetes: a GoDARTS study / Donnelly L.A., Doney A.S., Dannfald J. et al. // Pharmacogenet Genomics. 2008. Vol. 18, pp. 1021-1026. [PubMed: 18815589].

16. Variation in the 3-hydroxyl-3-methylglutaryl coenzyme a reductase gene is associated with racial differences in lowdensity lipoprotein cholesterol response to simvastatin treatment / Krauss R.M., Mangravite L.M., Smith J.D. et al. // Circulation. 2008. Vol. 117, pp. 1537-1544. [PubMed: 18332269].

17. Alternative splicing of 3-hydroxy-3-methylglutaryl coenzyme A reductase is associated with plasma low-density lipoprotein cholesterol response to simvastatin / Medina M.W., Gao F., Ruan W., Rotter J.I., Krauss R.M. // Circulation. 2008. Vol. 118, pp. 355-362.

18. Аронов Д.М., Лупанов В.П. Некоторые аспекты патогенеза атеросклероза // Атеросклероз и дислипидемии. 2011. №1. С. 48-56. 
19. Молекулярно-клеточные изменения при атеросклерозе / Аладинский В.А., Никифоров Н.Г., Темченко А.В., Котяшова С.Ю., Горлова О.Ю., Азарова И.Н., Орехов А.Н. // Клиническая медицина. 2015. Т. 93. №6. С. 14.

20. Аронов Д.М. Плейотропные эффекты статинов // Русский медицинский журнал. 2001. Т. 9. №13-14. С. 578-582.

21. Диагностика и корреляция нарушений липидного обмена с целью профилактики и лечения атеросклероза. Российские рекомендации, V пересмотр / Кухарчук В.В., Коновалов Г.А., Галявич А.С., Сусеков А.В., Сергиенко И.В., Ежов М.В., Семенова А.Е., Соловьева Е.Ю. // Атеросклероз. 2012. №2. С. 61-94.

\section{References}

1. Vsemirnaya Organizatsiya Zdravookhraneniya. Informatsionnyy byulleten’№ 317 «Serdechno-sosudistyye zabolevaniya» [World Health Organization. Newsletter number 317 "Cardiovascular diseases"]. http://www.who.int/mediasentre/ fastsheets/fs317/ru/index.html (accessed September 15, 2018).

2. Kathiresan S., Willer C.J., Peloso G.M. et al. Common variants at 30 loci contribute to polygenic dyslipidemia. Nat Genet, 2009, Vol. 41(1), pp. 56-65.

3. Kathiresan S., Melander O., Anevski D. et al. Polymorphisms associated with cholesterol and risk of cardiovascular events. $N$ Engl J Med, 2008, V. 358, pp. 1240-1249. [PubMed: 18354102].

4. Kathiresan S., Melander O., Guiducci C. et al. Six new loci associated with blood low-density lipoprotein cholesterol, high-density lipoprotein cholesterol or triglycerides in humans. Nat Genet, 2008, Vol. 40(2), pp. 189-197.

5. Pickin D.M., McCabe C.J., Rams L.E. et al. Cost effectiveness of HMG-CoA reductase inhibitor (statin) treatment related to the risk of coronary heart disease and cost of drug treatment. Heart, 1999, Vol. 82, pp. 325-332.

6. Postmus I., Trompet S., Deshmukh H. A. et al. Pharmacogenetic meta-analysis of genome-wide association studies of LDL cholesterol response to statins. Nat Commun, 2014, Vol. 5. P. 5068.

7. Thompson J.F., Hyde C.L., Wood L.S. et al. Comprehensive Whole-Genome and Candidate Gene Analysis for Response to Statin Therapy in the Treating to New Targets (TNT) Cohort. Circulation Cardiovascular Genetics, 2009, Vol. 2, pp. 173-181. [PubMed: 20031582].

8. Ference B.A. et al. Effect of naturally random allocation to lower low-density lipoprotein cholesterol on the risk of coronary heart disease mediated by polymorphisms in NPC1L1, HMGCR, or both: a $2 \times 2$ factorial Mendelian randomization study. Journal of the American College of Cardiology, 2015, Vol. 65, N. 15, pp. 1552-1561. 
9. Würtz P., Q. Wang, P. Soininen. Metabolomic profiling of statin use and genetic inhibition of HMG-CoA reductase. Journal of the American College of Cardiology, 2016, vol. 67, no 10, pp. 1200-1210.

10. Burkhardt R., Kenny E. E., Lowe J. K. Common SNPs in HMGCR in micronesians and whites associated with LDL-cholesterol levels affect alternative splicing of exon13. Arteriosclerosis, Thrombosis, and Vascular Biology, 2008, vol. 28, pp. 2078-2084.

11. Sharpe L.J., Brown A.J. Controlling cholesterol synthesis beyond 3-hydroxy-3-methylglutaryl-CoA reductase (HMGCR). Journal of Biological Chemistry, 2013, T. 288, №26, pp. 18707-18715.

12. Chung J.Y., Cho S.K., Oh E.S. et al. Effect of HMGCR variant alleles on low-density lipoprotein cholesterol-lowering response to atorvastatin in healthy Korean subjects. J Clin Pharmacol, 2012, Vol. 52, pp. 339-346.

13. Medina M.W., Krauss R.M. The role of HMGCR alternative splicing in statin efficacy. Trends in Cardiovascular Medicine, 2009, vol. 19, pp. 173-177.

14. Leduc V., Bourque L., Poirier J., Dufour R. Role of rs3846662 and HMGCR alternative splicing in statin efficacy and baseline lipid levels in familial hypercholesterolemia. Pharmacogenetics and Genomics, 2016, vol. 26, no. 1, pp. 109-119.

15. Donnelly L.A., Doney A.S., Dannfald J. et al. A paucimorphic variant in the HMG-CoA reductase gene is associated with lipid-lowering response to statin treatment in diabetes: a GoDARTS study. Pharmacogenet Genomics, 2008, Vol. 18, pp. 1021-1026. [PubMed: 18815589].

16. Krauss R.M., Mangravite L.M., Smith J.D. et al. Variation in the 3-hydroxyl-3-methylglutaryl coenzyme a reductase gene is associated with racial differences in lowdensity lipoprotein cholesterol response to simvastatin treatment. Circulation, 2008, Vol. 117, pp. 1537-1544. [PubMed: 18332269].

17. Medina M.W., Gao F., Ruan W., Rotter J.I., Krauss R.M. Alternative splicing of 3-hydroxy-3-methylglutaryl coenzyme A reductase is associated with plasma low-density lipoprotein cholesterol response to simvastatin. Circulation, 2008, Vol. 118, pp. 355-362.

18. Aronov D.M., Lupanov V.P. Nekotoryye aspekty patogeneza ateroskleroza [Some aspects of the pathogenesis of atherosclerosis]. Ateroskleroz $i$ dislipidemii [Atherosclerosis and dyslipidemia], 2011, №1, pp. 48-56.

19. Aladinskiy V.A., Nikiforov N.G., Temchenko A.V., Kotyashova S.Yu., Gorlova O.Yu., Azarova I.N., Orekhov A.N. Molekulyarno-kletochnyye izmeneniya pri ateroskleroze [Molecular and cellular changes in atherosclerosis]. Klinicheskaya meditsina [Clinical medicine], 2015, V. 93, №6/ P. 14. 
20. Aronov D.M. Pleyotropnyye effekty statinov [Pleiotropic effects of statins]. Russkiy meditsinskiy zhurnal [Russian Medical Journal], 2001, Vol. 9, No. 1314, pp. 578-582

21. Kukharchuk V.V., Konovalov G.A., Galyavich A.S., Susekov A.V., Sergiyenko I.V., Yezhov M.V., Semenova A.Ye., Solov'yeva Ye.YU. Diagnostika i korrelyatsiya narusheniy lipidnogo obmena s tsel'yu profilaktiki i lecheniya ateroskleroza. Rossiyskiye rekomendatsii, $\mathrm{V}$ peresmotr [Diagnosis and correlation of lipid metabolic disorders for the prevention and treatment of atherosclerosis. Russian recommendations, V revision]. Ateroskleroz [Atherosclerosis], 2012, №2, pp. 61-94

\section{ДАННЫЕ ОБ АВТОРАХ}

Оседко Алексей Владимирович, биолог Центральной научно-исследовательской лаборатории

ФГБОУ ВО Красноярский государственный медицинский университет имени проф. В. Ф. Войно-Ясенеикого МЗ РФ

ул. Партизана Железняка 13, г. Красноярск, 660022, Российская Федерачия

osedko.alex@live.ru

Котловский Михаил Юрьевич, доктор медицинских наук, научный сотрудник лаборатории лекарственной токсикологии НИИФиРМ им. Е.Д. Гольдберга

Томский НИМЦ

пр. Ленина, 3, г. Томск, 634028, Российская Федераџия

m.u.kotlovskiy@mail.ru

Оседко Ольга Яковлевна, биолог Центральной научно-исследовательской лаборатории

ФГБОУ ВО Красноярский государственный медиџинский университет имени проф. В. Ф. Войно-Ясенецккого МЗ РФ

ул. Партизана Железняка 13, г. Красноярск, 660022, Российская Федерачия

osedkoolga@yandex.ru

Дыгай Александр Михайлович, доктор медицинских наук, профессор, академик РАН, заслуженный деятель науки РФ, научный руководитель НИИФиРМ им. Е.Д. Гольдберга Томского НИМЦ, заместитель 
академика-секретаря Отделения медицинских наук РАН - руководитель секции медико-биологических наук

Томский НИМЦ

пр. Ленина, 3, г. Томск, 634028, Российская Федерация

pharm@tnimc.ru

\section{DATA ABOUT THE AUTHORS}

Osedko Aleksey Vladimirovich, Biologist

Krasnoyarsk State Medical University

1z, Partizan Zheleznyak Str., Krasnoyarsk, 660022, Russian Federation osedko.alex@live.ru

SPIN-code: $4622-5171$

ORCID: 0000-0003-2424-5734

ResearcherID: B-6157-2019

Kotlovskiy Michael Yurevich, $\mathrm{PhD}$, Researcher of Drug Toxicology Laboratory of Goldberg Research Institute of Pharmacology and Regenerative Medicine

Tomsk National Research Medical Center

3, Lenin av., Tomsk, 634028, Russian Federation

m.u.kotlovskiy@mail.ru

Osedko Olga Yakovlevna, Biologist

Krasnoyarsk State Medical University

1z, Partizan Zheleznyak Str., Krasnoyarsk, 660022, Russian Federation osedkoolga@yandex.ru

Dygai Alexander Mikhaylovich, $\mathrm{PhD}$, Professor, Academician of RAS, honored worker of science of the Russian Federation, Scientific Supervisor of Goldberg Research Institute of Pharmacology and Regenerative Medicine of Tomsk National Research Medical Center of RAS, Deputy Academician - Secretary of Department of Medical Sciences of RAS Head of Section of Biomedical Sciences

Tomsk National Research Medical Center

3, Lenin av., Tomsk, 634028, Russian Federation pharm@tnimc.ru 